\title{
CCND2 Gene Amplification
}

National Cancer Institute

\section{Source}

National Cancer Institute. CCND2 Gene Amplification. NCI Thesaurus. Code 1131785.

A molecular genetic abnormality indicating the presence of multiple copies of the CCND2 gene. 